\title{
Development of food photographs to improve the portion size estimation among South Asian
}

\author{
W. Husain ${ }^{1}$ and S. Khokhar ${ }^{1}$ \\ ${ }^{1}$ School of Food Science and Nutrition, University of Leeds, Leeds LS2 9JT, UK
}

Measurement errors often occur when assessing the diet of individuals due to the difficulties of estimating food portion size ${ }^{(1)}$. The weighed food record is the optimum method to estimate food intake. However, it is associated with high respondent burden and time $\operatorname{costs}^{(2)}$. Moreover, to our knowledge, ethnic specific food photographs for South Asians in the UK have not been previously developed. Therefore, there is a need to develop tools to estimate the amount of food consumed more accurately among this population. The aim of this study is to develop and test photographic portion sizes of commonly consumed foods by South Asian children to enhance the estimation of food portion sizes.

Participants were invited to compare a set of coloured food photographs with the actual portion sizes of foods served on a plate. In all, thirty-sixparticipants completed the food estimation sessions. A total of 360 estimations were carried out by Indian ( $n$ 150) and Pakistani ( $n$ 210) mothers. The degree of accuracy and percentage of correct estimations were calculated. Statistical calculations were performed using SPSS software version 17.0. Descriptive statistics were used to assess the characterisation of the participant's response for the actual food as compared with photograph.

\begin{tabular}{|c|c|c|c|c|c|c|c|c|c|c|}
\hline & Veg curry & Cereal & Biryani & Chicken curry & Dhal & Fruit salad & Keema & Palak & Rice & $\overline{\text { Soup }}$ \\
\hline \multicolumn{11}{|l|}{$\overline{\text { Indian }}$} \\
\hline Actual* & 90 & 60 & 120 & 60 & 90 & 30 & 120 & 20 & 60 & 90 \\
\hline Estimated* & 88 & 55 & 120 & 70 & 84 & 30 & 116 & 20 & 57.3 & 78 \\
\hline SD & 7.7 & 10.9 & 0.0 & 14.6 & 20.3 & 0.0 & 10.5 & 0.0 & 7.03 & 18.9 \\
\hline Sig. (two-tailed) & 0.33 & 0.09 & - & 0.02 & 0.27 & - & 0.16 & - & 0.16 & 0.03 \\
\hline Accuracy** & -2.2 & -8.3 & 0.0 & 16.7 & -6.7 & 0.0 & -3.3 & 0.0 & -4.5 & -13 \\
\hline Correct estimation** & 93 & 80 & 100 & 67 & 54 & 100 & 87 & 100 & 87 & 67 \\
\hline \multicolumn{11}{|l|}{ Pakistani } \\
\hline Actual* & 60 & 60 & 120 & 60 & 90 & 30 & 120 & 20 & 60 & 30 \\
\hline Estimated* & 62.9 & 55.7 & 128.6 & 55.7 & 91.4 & 31.4 & 112.9 & 20 & 58.1 & 32.9 \\
\hline SD & 9.02 & 8.40 & 21.5 & 14.3 & 22.2 & 6.5 & 13.1 & 0.0 & 6.02 & 9.02 \\
\hline Sig. (two-tailed) & 0.16 & 0.03 & 0.08 & 0.18 & 0.77 & 0.32 & 0.02 & - & 0.16 & 0.16 \\
\hline Accuracy** & 4.8 & -7.1 & 7.1 & -7.1 & 1.6 & 4.8 & -6.6 & 0.0 & -3.2 & 9.5 \\
\hline Correct estimation** & 90.5 & 76.2 & 85.7 & 76.2 & 47.6 & 95.2 & 76.2 & 100 & 90.5 & 90.5 \\
\hline
\end{tabular}

Positive responses were taken as over-estimations and negative responses taken as under-estimations.

*The value in $(\mathrm{g})$, ** The value in percentage.

Food portion photographs may enhance both the reliability and validity of estimated dietary intakes in the South Asian population. This was demonstrated by the high percentage of accurately estimated portion sizes in this study (83\%). Under/over-estimation was recorded for certain foods; however, these values were minimal and might be within the expected range due to difference of perception of individuals.

1. Lucas F, Niravong M, Villeminot S et al. (1995) J Hum Nutr Diet 8, 65-74.

2. Young LR \& Nestle M (1995) Nutr Rev 53, 149-158. 